\title{
Anaphylaxis after surgical excision of subcutaneous infection with parasitic Dirofilaria: a case report
}

\author{
Brian WC Luk *, MB, BS, CN Cheung, MB, ChB, FHKAM (Orthopaedic Surgery), YF Chan, MB, BS, FHKAM (Orthopaedic Surgery)
}

\author{
Department of Orthopaedics and Traumatology, Pok Oi Hospital, Hong Kong
}

* Corresponding author: lukwingchung@gmail.com

Hong Kong Med J 2021;27:297-9

https://doi.org/10.12809/hkmj208675

\section{Case report}

In January 2018, a 21-year-old man with good past health presented with a 2-week history of left forearm painless lump. He had no fever. The lump was $30 \mathrm{~mm}$ in diameter with no evidence of inflammation. Preoperative diagnosis was a sebaceous cyst and preoperative blood tests were not routinely performed.

Surgical excision was performed under local anaesthesia with lidocaine and application of a tourniquet. Intra-operatively, a whitish-yellowish 25-mm subcutaneous nodule surrounded by dense adhesions without a definite border was removed. The nodule was firm and multi-lobulated with multiple feeding vessels. Although en bloc excision with a 5-mm margin was attempted, the dense fibrous mass was partially breached during dissection due to scarring.

After tourniquet release, the patient developed flushing, dizziness, diarrhoea, hypotension, and sinus tachycardia. He had no respiratory distress but the clinical diagnosis was anaphylactic shock. He was stabilised with fluid resuscitation and intravenous adrenaline. Laboratory tests showed an elevated white blood cell count (WBC) at $13.6 \times 10^{9} / \mathrm{L}$ (reference range: $3.9-10.7 \times 10^{9} / \mathrm{L}$ ), neutrophil predominance at $85.9 \%$ (reference: 38\%-76\%), and low eosinophil count of only $0.027 \times 10^{9} / \mathrm{L}$ (reference: $<0.45 \times 10^{9} / \mathrm{L}$ ) and $0.2 \%$ of total WBC. Blood tests were otherwise unremarkable. Serum mast cell tryptase level was $46.2 \mu \mathrm{g} / \mathrm{L}$ immediately after surgery but dropped to $3.3 \mu \mathrm{g} / \mathrm{L}$ after 24 hours. Erythrocyte sedimentation rate or C-reactive protein were not measured. The patient remained well and was discharged home the next day.

The patient had no known history of allergy and skin allergy test for exposed agents including lidocaine was negative. On further questioning, he revealed regular contact with horses located in a countryside barn but no contact with other animals. He reported skin erythema (Fig 1) prior to swelling onset but had presumed this was due to a mosquito bite.

Microscopy of the nodule revealed a piece of fibro-fatty tissue with mixed inflammatory cell infiltrate and dense eosinophilic infiltrate (Fig 2a), and a $0.72 \mathrm{~mm} \times 0.29 \mathrm{~mm}$ fragment of degenerated parasite rimmed by foamy histiocytes (Fig 2b). There was no evidence of malignancy. The surgical margin measured from the edge of the surrounding granulomatous inflammation to the closest edge of the excised specimen was $0.82 \mathrm{~mm}$. Further molecular study by polymerase chain reaction and DNA sequencing based on Filarioidea cytochrome oxidase subunit I (cox1) and specific $12 \mathrm{~S}$ ribosomal RNA (12S rRNA) gene revealed the parasite to be Dirofilaria hongkongensis. ${ }^{1}$

The patient remained symptom-free and differential WBC and C-reactive protein were normal at 6 months after surgery. No antiparasitic therapy was deemed necessary by microbiologists.

\section{Discussion}

Dirofilaria hongkongensis has been proposed as a novel species causing zoonotic filariasis in humans and is a possible cause of unresolved subcutaneous nodules in Hong Kong. ${ }^{2}$ This is the first reported case worldwide of anaphylactic shock following excision of subcutaneous dirofilariasis in a human.

Zoonotic filariae are transmitted to humans through the bite of an infected arthropod such as mosquitoes. However, they cannot grow to maturity in accidental hosts such as humans. ${ }^{3}$ The pathogenesis is localised foreign body reaction around a moribund parasite. The absence of a host inflammatory response in the asymptomatic period suggests death of the worm due to an unfavourable host environment, rather than host immunity. ${ }^{3}$ Asymptomatic survival and growth of the parasite may continue for $\geq 6$ months. The lesion becomes clinically noticeable due to granulomatous reaction with tissue scarring and can present as a subcutaneous or ocular lesion, and rarely as lymphadenopathy and nodules in deeper tissues such as the lungs. In our patient, the subcutaneous dirofilariasis presented as a painless lump in his forearm, without any symptoms or signs of inflammation. The patient reported some skin erythema prior to the onset of the swelling. The erythema could have been caused by a mosquito bite, 


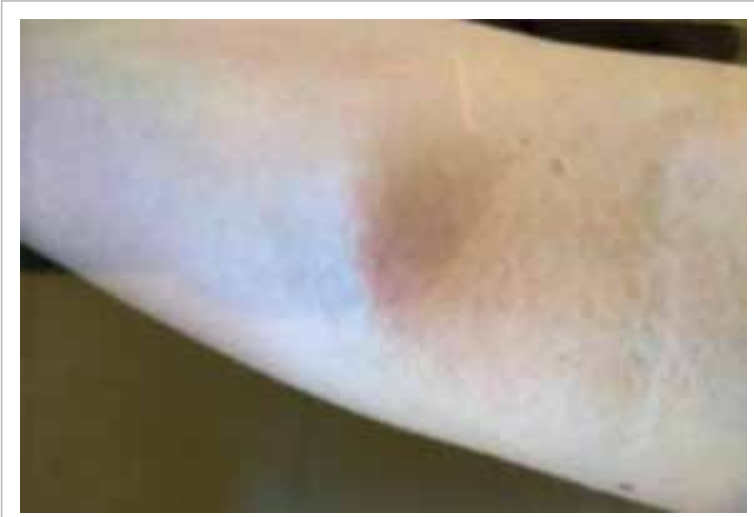

FIG I. Clinical photograph of a 2 I-year-old patient with dirofilariasis showing the development of skin swelling on the left proximal volar forearm after the onset of erythema which is a possible route of parasite transmission. The absence of pain, warmth, or erythema over the mass would suggest the parasite did not trigger a significant inflammatory response in our patient. After the parasite's death, the remaining material could be shielded off from the host tissue by a dense fibrous tissue envelope, producing a lump which was otherwise asymptomatic.

Careful history taking may reveal exposure to animals. Subcutaneous infections are small $(0.5-1.5 \mathrm{~cm})$ and discrete. Pain or sense of a moving worm may be present. Blood tests for eosinophilia and elevated inflammatory markers might be useful, but the absence of systemic inflammation is common ${ }^{3}$ and blood test results may be unremarkable. In our patient, blood tests were not taken preoperatively, as the clinical impression of the mass was a sebaceous cyst, with the absence of signs of inflammation. Postoperative blood tests showed neutrophilia instead of eosinophilia, but the results were likely affected by the anaphylaxis.

Among around 40 species of Dirofilaria, $D$ immitis and $D$ repens account for most cases of infection in humans. Dirofilaria immitis is commonly known as "dog heartworm" and has a cosmopolitan distribution. Hou et $\mathrm{al}^{4}$ reported seropositivity in $30.6 \%$ of stray dogs and $15.6 \%$ of domestic dogs in north-eastern China. Wang et $\mathrm{al}^{5}$ reported a $0 \%$ to $7.4 \%$ seroprevalence in dogs in coastal cities in south-eastern China. Dirofilaria repens is prevalent worldwide including Southeast Asia. Dirofilaria hongkongensis was first proposed as a distinct species in 2012, following three cases of human infection. ${ }^{2}$ In stray dogs in Hong Kong, the seroprevalence of $D$ hongkongensis is $3 \%,{ }^{2}$ and that of $D$ immitis is $10 \%{ }^{6}$

Molecular study in nucleotide sequencing of cytochrome oxidase subunit 1 ( $\operatorname{cox} 1)$ gene and the $12 \mathrm{~S}$ ribosomal RNA (12S rRNA) gene is useful in the

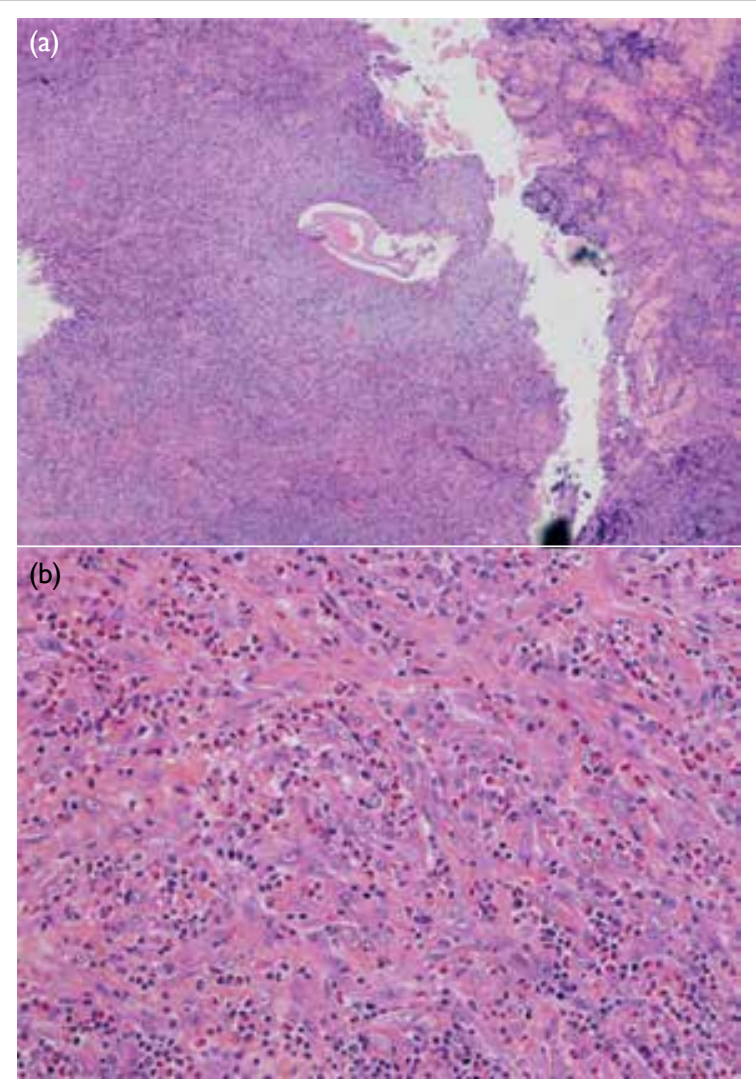

FIG 2. Histopathological results from the same patient showing (a) degenerated parasite with ghost outline of the muscular layer and tubular structure, measuring $0.72 \mathrm{~mm} \times$ $0.29 \mathrm{~mm}$ (haematoxylin and eosin, $\times 100$ ) and (b) mixed inflammatory cell infiltrate with dense eosinophilic infiltrate (haematoxylin and eosin, $\times 400$ )

identification of Dirofilaria species, taking reference from GenBank data. The cox1 gene and $12 \mathrm{~S}$ rRNA gene specific to $D$ hongkongensis were identified (GenBank accession number NC_031365). Simpler diagnostic tests would be less reliable; for example, morphological identification depends on the quality of histopathological specimen, and in our case only parasitic fragments were found. Retrospective molecular study could also be performed on the stored specimen for epidemiological studies.

Parasitic materials are foreign antigens that may trigger a type I immunoglobulin E-mediated hypersensitivity reaction. Dirofilaria immitis extract can result in shock and elevated plasma histamine level in dogs, ${ }^{7}$ while hydatid cyst (Echinococcus spp) rupture has been associated with anaphylactic shock. ${ }^{8}$ We believe the partial breach of the parasitic tissue envelope during our surgical dissection led to contact of parasitic material with host tissue. This contact, in turn, caused the hypersensitivity reaction and anaphylactic shock in our patient. 
We recommend complete en bloc excision of lesions suspected to be caused by dirofilariasis to prevent anaphylaxis, especially when surgeons encounter dense adhesions or multiple feeding vessels. Further study is required to ascertain the necessary margin of excision to avoid inadvertent breakage of the tissue envelope. Up to $75.4 \%$ of parasitised humans experience chronic urticaria. ${ }^{9}$ In our patient, the capsule was breached during dissection and sudden allergen release may have triggered the anaphylactic cascade. Antiparasitic medication is likely unnecessary if the parasite can be removed intact.

Anaphylactic shock can cause sudden haemodynamic collapse. It is characterised by acute onset of hypotension after allergen exposure, or the combination of cutaneous, cardiopulmonary or gastrointestinal manifestations. ${ }^{10}$ The importance of routine monitoring, timely detection and cardiopulmonary stabilisation cannot be overemphasised. Plasma tryptase or histamine level may serve as a diagnostic adjunct in doubtful cases. Fluid resuscitation, supplemental oxygen, and epinephrine injection are indicated as effective treatments of anaphylactic shock.

\section{Author contributions}

All authors contributed to the concept of study, acquisition and analysis of data, drafting of the manuscript, and critical revision of the manuscript for important intellectual content. All authors had full access to the data, contributed to the study, approved the final version for publication, and take responsibility for its accuracy and integrity.

\section{Conflicts of interest}

All authors have disclosed no conflicts of interest.

\section{Funding/support}

This study received no specific grant from any funding agency in the public, commercial, or not-for-profit sectors.

\section{Ethics approval}

The patient was treated in accordance with the Declaration of Helsinki. The patient provided verbal informed consent for publication of this de-identified case report, including clinical photos.

\section{References}

1. Dang TC, Nguyen TH, Do TD, et al. A human case of subcutaneous dirofilariasis caused by Dirofilaria repens in Vietnam: histologic and molecular confirmation. Parasitol Res 2010;107:1003-7.

2. To KK, Wong SS, Poon RW, et al. A novel Dirofilaria species causing human and canine infections in Hong Kong. J Clin Microbiol 2012;50:3534-41.

3. Eberhard ML. Zoonotic filariasis. In: Guerrant R, Walker D, Weller P, editors. Tropical Infectious Diseases: Principles, Pathogens, and Practice. 3rd ed. New York: Elsevier; 2011: 750-8.

4. Hou H, Shen G, Wu W, et al. Prevalence of Dirofilaria immitis infection in dogs from Dandong, China. Vet Parasitol 2011;183:189-93.

5. Wang J, Zhu X, Ying Z, et al. Prevalence of Dirofilaria immitis infections in dogs and cats in Hainan Island/ Province and three other coastal cities of China based on antigen testing and PCR. J Parasitol 2019;105:199-202.

6. Wong SS, Teng JL, Poon RW, et al. Comparative evaluation of a point-of-care immunochromatographic test SNAP 4DX with molecular detection tests for vector-borne canine pathogens in Hong Kong. Vector Borne Zoonotic Dis 2011;11:1269-77.

7. Kitoh K, Katoh H, Kitagawa H, Nagase M, Sasaki N, Sasaki Y. Role of histamine in heartworm extract-induced shock in dogs. Am J Vet Res 2001;62:770-4.

8. Khanna P, Garg R, Pawar D. Intraoperative anaphylaxis caused by a hepatic hydatid cyst. Singapore Med J 2011;52:e18-9.

9. Minciullo PL, Cascio A, Gangemi S. Association between urticaria and nematode infections. Allergy Asthma Proc 2018;39:86-95.

10. Simons FE, Ardusso LR, Bilò MB, et al. World allergy organization guidelines for the assessment and management of anaphylaxis. World Allergy Organ J 2011;4:13-37. 